\title{
Creating a Healthier Campus Community Using Action Research and Health Promotion Strategies: Students and Organizational Leaders as Partners
}

Claire Budgen, University of British Columbia Okanagan Campus, BC, Canada

Doris Callaghan, University of British Columbia Okanagan Campus, BC, Canada

Diane Gamble, University of British Columbia Okanagan Campus, BC, Canada

Robyn Wiebe, University of Victoria, BC, Canada

Christopher Reimer, University of British Columbia Okanagan Campus, B.C., Canada

Melissa Feddersen, University of British Columbia Okanagan Campus, BC, Canada

Shannon Dunn, University of British Columbia Okanagan Campus, B.C., Canada

Rob Johnson, University of British Columbia Okanagan Campus, B.C., Canada

Natalie McHugh, University of British Columbia Okanagan Campus, B.C., Canada

Heidi Morrison, University of British Columbia Okanagan Campus, B.C., Canada

Kelli Sullivan, University of British Columbia Okanagan Campus, B.C., Canada

Ian Cull, University of British Columbia Okanagan Campus, B.C., Canada

Alaa Abd-El-Aziz, University of Prince Edward Island, P.E.I., Canada

Abstract: Although young adults are generally healthy, they often engage in risky behaviours and establish lifestyle patterns that have costly immediate and long-term health impacts (e.g. poor nutrition, inactivity, substance misuse). Many young people attend colleges and universities making campuses an ideal setting for interventions. Setting based health promotion approaches have been used to improve health of populations and communities, including campus communities, however, creating change that is meaningful to students and also organizational leaders (non-students) has been difficult. In 2006 at a rapidly growing campus in Canada, a program of research was started to increase knowledge about healthy campus development. The VOICE Study uses community based participatory action re-

The International Journal of Health, Wellness and Society

Volume 1, 2011, http://HealthandSocietyJournal.com/, ISSN 2156-8960

(c) Common Ground, Claire Budgen, Doris Callaghan, Diane Gamble, Robyn Wiebe, Christopher Reimer,

Melissa Feddersen, Shannon Dunn, Rob Johnson, Natalie McHugh, Heidi Morrison, Kelli Sullivan, Ian

Cull, Alaa Abd-El-Aziz, All Rights Reserved, Permissions: cg-support@commongroundpublishing.com 
search methods in combination with setting based health promotion strategies. Students and organizational leaders (non-students) work as co-researchers and project partners to identify priority health issues and create health promoting change (individual and community levels). While the idea of campus community members working together on health related issues is appealing to many, diverse views exist about the responsibility of post-secondary institutions to promote health; some prefer an individual responsibility or consumer model. An ecosystem model of health and community informs this study. Photographic, quantitative and qualitative research methods have been used according to questions of interest. Action groups have been formed around diverse topics, for example, drinking water, "real" food, natural environment, physical activity, transportation and student space. Results indicate that the process of creating change through use of a methodological framework combining action research, setting based health promotion and youth/adult partnerships, is highly effective. Diverse students (youth) and organizational leaders (adults must be full partners throughout the process. Patience, persistence and a sense of humor are basic requirements. The results appear to be transferable to other settings when the egalitarian values embedded in the methodological framework are explicit, and the community designs the specifics (e.g. issues, actions) to fit their context. Study processes, outcomes, challenges and successes are discussed, followed by a case study on campus food to illustrate more specifically the use of the methodological framework and results.

Keywords: Youth and Adult Partnerships, Community Based Participatory Action Research, Healthy Community Development, Health Promoting Universities, Young Adult Health, Setting Based Health Promotion, Healthy Eating

\section{Introduction}

7 OUNG ADULTS (18-28 years) have been called a "neglected age group" in health care because although generally healthy, they often engage in risky behaviors and establish lifestyle patterns that have costly short and long-term health impacts. Young adult health problems include stress, unhealthy eating, physical inactivity, substance misuse, accidental injuries, sexually transmitted infections, internet misuse, anxiety, depression and suicidal behavior. These problems are largely preventable.

Many young people attend university and college, making campuses a favorable setting for interventions that promote young adult health and prevent injury and illness. Life on campus is a unique time of risk and opportunity as students often are newly away from home, experimenting with lifestyle choices and experiencing community membership outside family boundaries for the first time. Individual-focused healthy behavior models that concentrate on reducing risky and increasing health promoting behavior, probably are most familiar on campuses; however, ecological models of community health that take into account the interaction among students, environments, economics and health, are gaining interest (Hancock, 1993a, see FIGURE 1). 


\section{Health and Community Ecosystem Model}

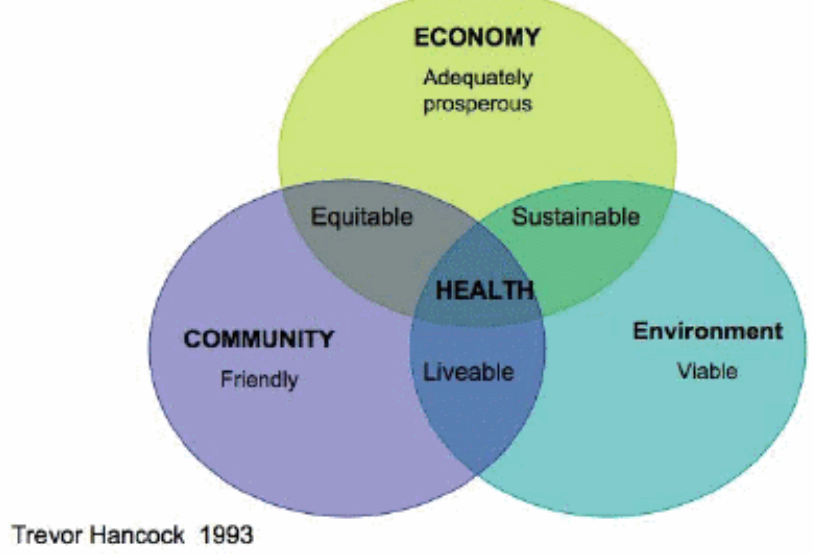

Figure 1

The World Health Organization's Healthy Cities/Healthy Communities movement offers a well-tested ecological model for improving the health of populations within communities (Hancock, 1993b). Health improvements result from strategies to increase citizen participation and community action, build healthy policy, create supportive environments, develop personal skills and reorient health services to increase prevention (WHO, Ottawa Charter, 1986). A spin off from Healthy Communities is the Healthy Campus/Health Promoting University movement. Related theory and research are explicating the emerging role of the health promoting organization, and the power and responsibility of universities and colleges to act as supportive environments for health (Doherty \& Dooris, 2006).

This setting-based view of health promotion inevitably takes investigators into the fray of values and ethics, arising from the operation of campuses as publicly responsible learning communities, and also, business organizations with "bottom line" priorities. Thus, while the ideals of the Healthy Campus/Health Promoting University movement are inspiring, enactment can be challenging. Diverse opinions exist about the role of a university or college to promote the health of students and the campus community. Some favor an individual choice or consumer model that reflects marketplace values. Others claim that costs of poor student health such as decreased academic success and increased need for health care (acute and chronic) are too high; and thus health promotion and prevention should be responsibilities of campus organizations.

Although numerous small and large scale healthy campus development programs and projects are described in the literature, process and outcomes have been challenging to evaluate and to generalize to other campuses, given the complexity of campus environments and changing nature of student populations. Overall in the literature, there is a call for more research and rigorous evaluation of approaches (Dooris \& Doherty, 2009). Although setting based health promotion might appear to be an ideal approach for healthy campus development, the literature depicts the two most common approaches as an organizational development model and a student project model (Reger, Williams, Kolar, Smith, \& William Douglas, 
2002; Xiangyang, Lan, Xueping, Tao, Yuzhen, \& Jagusztyn, 2003; Tsouros, Dowding, Thompson, \& Dooris, 1998). The organizational development model has been criticized for lack of relevance to students; and the student project model, for being difficult to sustain (Tsouros, et al., 1998). Although youth-adult partnerships have been linked with positive outcomes in the general community development literature (Checkoway, Allison, \& Montoya, 2005; Larson, Hansen, \& Moneta, 2006; Bader, Wanono, Hamden, \& Skinner, 2007), this approach was not seen in the healthy campus/health promoting university literature.

This manuscript reports the results of a study that investigated the effectiveness of a setting based approach to healthy campus development that incorporates a student driven-organizational development model and action research (VOICE Study \#1). The setting based approach consisted of health promotion strategies from the Ottawa Charter (WHO, 1986). Community based action research methods were used to guide the implementation of the health promotion strategies, and also, to link the work of students and organizational leaders and integrate systematic evaluation and research throughout the process. The campus-wide study framework and results are described first, and then a case example about food is presented to illustrate more specific use of the methodological framework and results.

\section{Study Goals}

A main goal of the study was to assess changes when a combined action research and setting based health promotion approach was used by students and organizational leaders working in partnership. Guided by action research principles, students and organizational leaders worked together as co-researchers and project partners to jointly design and take action to create health promoting changes relevant to student identified health priorities. Thus, we explored experiences, processes and outcomes at individual and community levels. For the study, organizational leaders were defined as non-students, that is, faculty, staff, administrators and campus business people. Another goal of the study was to increase knowledge about student and organizational leader experiences and participation when working in co-researcher partnerships however a description of these results is beyond the scope of this article.

\section{Context}

The study took place at a Canadian university campus undergoing rapid growth. The student population increased from about 2500 to 6500 during the study; the student resident population increased from 350 to over 1500 . Growth is continuing. The study was funded by an internal research grant and external grants from the British Columbia Medical Services Foundation, the Canadian Nurses' Foundation and Health Canada. The university research ethics board approved the study.

\section{Methods}

A community based participatory action research (CB-PAR) approach was used (Minkler \& Wallerstein, 2003). CB-PAR has three interconnected goals: research, education and action, and is a process using various methods rather than a distinct method. Thus, researchers can explore changing determinants of health and interactions in communities (Satcher, 2005). Collaborative and equitable partnerships enable the community and researchers to determine 
the research agenda and jointly share in iterative cycles of community dialogue, planning, data collection and analysis, disseminating and verifying results, using results to educate and taking action to improve health (Wallerstein \& Duran, 2003). CB-PAR allows for ongoing development of methods appropriate to study aims. The design evolves through negotiation and dialogue between the community and researchers with community members functioning as co-researchers (see Figure 2). The research, action and education components of CB-PAR complement the action strategies of the setting based health promotion approach.

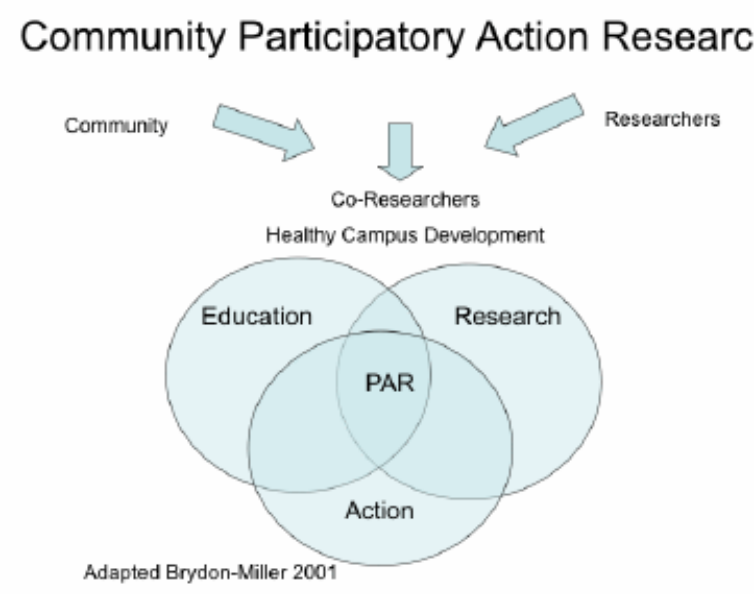

Figure 2

\section{Research Team and Recruitment of Co-researchers and Project Partners}

The core research team comprised a mix of multidisciplinary faculty, senior university administrators, managers of university departments and a doctoral student. Each had expertise relevant to the study. A research consultation group of campus and external community members provided additional expertise (e.g. reviewed plans, gave advice). Consistent with the study aims, the investigator and consultant structure was designed to engage all sectors of the campus community. As the study progressed, members of the campus community became co-researchers and project partners for periods of time, as depicted in Figure 2.

All members of the campus community, students and organizational leaders, were invited to become co-researchers and project partners via posters at campus events and on "info boards". Undergraduate students became involved through course credit options, as employed research assistants or by volunteering. Organizational leaders were invited to participate when they had expertise relevant to specific student identified health interests. Students were asked to sign confidentiality agreements and were given research and project training; organizational leaders were asked to maintain research guidelines. Everyone agreed to work collaboratively. 


\section{Ongoing Iterative Study Process}

This healthy campus development study, VOICE \#1, took place from 2006-2009. The first year was pilot work to test methods, develop relationships across the campus and obtain external funding. Study phases comprised iterative cycles of campus community engagement and assessment, issue identification and critique, partnership formation, planning, action, reflecting and sustaining. The congruence between CB-PAR methods and setting based health promotion is readily apparent in these phases (Budgen, Cameron, \& Bartfay, 2010; Freire, 1970/1993; Ministry of Health, B.C., 1989; Ridgley, Maley, \& Skinner 2004). The study phases first were enacted campus wide and then were repeated on a smaller scale to support action groups that were formed around priority health-related issues.

After the pilot work, each year between 60-80 students worked as co-researchers, either in large groups when campus wide work was needed or in small, issue focused "healthy campus" action groups. Work timelines were shaped by the academic year (mid-term and semester end). The process of engaging with the campus continued as needed over time to ensure community views were understood and also that change (positive or negative) was assessed following actions taken.

\section{Data Collection}

Data of interest were pictures, words and numbers. Primary data collection methods were surveys (campus wide and issue specific), Photovoice, field notes and document review. Secondary data collection methods were designed to provide information for issue specific action groups. Surveys and interviews included minimally structured questions to facilitate collection of people's views and experiences (qualitative data), and also, highly structured questions to enable ranking and rating of items and collection of demographic information (quantitative data). Field notes provided descriptive data about the study process, and document reviews (e.g. of meeting minutes, policy documents) added data about practices, policies and changes.

Data were collected as needed throughout the study to enable description of the overall study, to ensure research goals were adequately explored and to support specific action groups. In other words, baseline and follow up data were collected to enable assessment of change and to provide formative information to guide action groups (for example, taste testing to measure preferences for various foods for the VOICE Food Action Group).

Photovoice is a participatory method by which people can represent their community through photos, record community strengths and concerns, promote critical dialogue about important community issues through discussions of the photos, and mobilize people towards change (Wang, 2003; Wang \& Burris, 1997). Student researchers used digital cameras initially to photograph everyday campus realities in relation to health and later to record changes. More than 500 photos were archived (about 300 in the initial assessment and 200 as the study progressed). Most pictures were of the environment, however, if any person was identifiable, consent was obtained.

In the initial community assessment at the beginning of the second year and following pilot work, results from Photovoice were used to develop the Community Dialogue survey. After taking photos of health-related campus issues of significance to them, student researchers analyzed the photos for themes with the support of the core research team. The student re- 
searchers decided which thematic issues were most significant overall and used these to design a ranking question on the Community Dialogue survey. The campus wide Community Dialogue survey questions were: What makes a healthy campus? What is healthy about this campus? What is unhealthy? What would make the situation better? The final ranking question asked participants to select 3 issues most important to improve, from the list of priority issues originating from Photovoice results. Action groups then were formed to deal with the issues that were most highly ranked.

At the end of the second year of the study, the campus community was reassessed. In this second Community Dialogue survey, campus community members were asked whether they had noticed any health related campus changes over the past 8 months (positive or negative), what the changes were (if any), and what might have contributed to these changes. Also student researchers used Photovoice methods to document action group activities and associated campus changes.

In the third year of the study, action group work continued, however, the focus shifted to reflection, renewal and sustaining positive change while continuing to respond to the rapid campus growth and changing context.

\section{Data Analysis and Interpretation}

Quantitative data were analyzed using descriptive statistics (Excel) and qualitative data (including photographs) were analyzed for concepts and themes (Morse, 1999). As mentioned earlier, groups of student researchers analyzed data with support from the core research team; all results were compared and disseminated as part of the CB-PAR and setting based health promotion processes. Results were returned at action group meetings and campus wide forums for comment and interpretation, to inform and sustain action and to further engage the campus in the action research process. Photographs were shown to facilitate inductive questioning and discussion around meanings, issues and significance (Wang, 2003). The triangulation (Denzin \& Lincoln, 2000) of multiple kinds of data, collection methods and investigators was intended to increase the validity of results.

\section{Sample Recruitment}

All students and non-student members of the campus community were invited to participate in community dialogue processes, with informed consent. Anyone who wanted to "voice" their views was welcome to complete a questionnaire and asked if they would like to contribute to improving situations in which they were interested (i.e. via an action group). Student researchers distributed survey questionnaires on clipboards at "info booths" and on "walkabouts" around the campus. Consistent with CB-PAR guidelines (Green, George, Daniel, Frankish, Herbert, Bowie, \& O'Neil, 2003), these methods were intended to recruit participants from diverse sectors of the campus. Sample recruitment progressed quickly throughout the study, as long as the rhythms of campus life were taken into account (e.g. not during the rush to morning classes). The researchers endeavored to create "buzz" across the campus about people "raising their voices" and contributing to the creation of a vibrant community. The student researchers' enthusiasm resonated throughout the process.

For each of the data collection methods used, sampling continued until data became redundant and/or the sample was adequately representative of the campus population, for ex- 
ample, on variables such as student gender, year of study, type of academic program, place of residence and international or local status.

\section{Limitations}

Prior to consideration of results, the reader is reminded that a main feature and limitation of CB-PAR is that many factors and events (variables) other than the research activities are continuously influencing individuals and communities over time. Field notes and other documents were used to record the campus community "story" of processes, actions and outcomes over the span of the study; however, a community story always is incomplete and the links between actions and outcomes, even when appearing quite clear, still may be influenced by unknown factors. Thus those interested in learning from and using the study results will need to determine the transferability of findings to their settings.

\section{Results}

First, results are presented that are pertinent to the goal: to assess changes relevant to identified priority health issues and actions taken. Second, a case study on campus food is presented to illustrate more specifically the application of an action research and setting based health promotion approach to a specific campus health issue, actions taken and results.

The initial campus wide Community Dialogue survey in 2007 elicited an enthusiastic response from students and other community members $(n=1268)$. External community media coverage added to the excitement about a university "studying itself". The student population was about 5,500 at that time. The quantitative results indicated that the issues most important to improve were campus food, drinking water, fitness/recreation opportunities, parking and student space (not surprising given the rapid growth of the campus population). The next highest ranked issues important to improve were recycling/sustainability, cycling/transportation, the natural environment, smoking, safety (linked with extensive building construction) and alcohol use.

Eight months after the campus wide research process started, Photovoice and the Community Dialogue survey were repeated to re-assess the community. Quantitative survey results indicated positive improvements on many issues and limited, mixed or negative changes on a few issues. The most noticed improvements were about campus food, drinking water and recycling/sustainability. To facilitate interpretation, quantitative results were compared with qualitative results from Community Dialogue survey questions, Photovoice "before and after" pictures, and documents such as semester mini-reports from action groups.

The mid-point results were effectively used to shape the last year of the study as indicated by follow through on priority issues, endeavors to sustain positive changes and adjustment of action strategies to incorporate many positive campus changes such as new buildings and services. Actions continued to support inclusion of health promoting features within new campus developments such as low cost healthy food options at the new Student Union outlets. Action group membership evolved over time, according to work to be accomplished, changes in organizational leader positions, completion of courses by students and student and organizational leader interests. Participation remained high.

Initial and later results were returned to the community using multi-media strategies and forums. The use of results from multiple data sources in combination with the photographs 
from Photovoice stimulated the timely development of common understandings among community members, in depth critique of issues and motivation to make changes "ourselves". The action groups that formed around each issue successfully enabled interested students and organizational leaders (non-students) to work in partnership to design and implement change strategies that were tailored to the specific issue. Challenges in finding common ground from which to work arose especially often in groups where participant agendas were very different. The effectiveness of the wide range of strategies that were created to influence change was attributed largely to careful alignment of strategies with the qualitative Community Dialogue survey results. The qualitative results provided rich information about community members' experiences and suggestions for improving the campus at individual and community levels. Also, changes were necessitated and supported by the rapid growth of the campus. To ensure that results continued to inform the ongoing process, at the end of each semester student researchers prepared an issue specific mini-report to document actions, outcomes and recommendations for follow up.

In the case study of campus food, food improvement is shown to be of high importance to the campus community, and also, the story (process, actions and results) illustrates clearly the effectiveness and challenges of CB-PAR and setting based health promotion on a university campus. Further, as food security is an issue of global interest, the case may have wider applicability than some of the campus issues (Government of Southern Australia, 2010; U.S. Department of Health and Human Services, 2008).

\section{Case Study: Campus Food}

\section{The Campus Food Context}

The nature of universities whereby large numbers of young adults reside and spend long hours each day makes the availability of food a necessity and food services a challenge. On the study campus, food was provided through exclusive contracts with food, beverage and snack vendors. Outlets included a large cafeteria, deli, residence store and beverage and snack vending machines. The Student Union "pub" served packaged snack food. Major changes in the food services were planned as the student population was expected to triple in size with the residence population expanding five times. The majority of resident students were first year students with limited kitchen access and with an obligatory meal plan that was intended to support good nutrition. The researchers were interested in influencing the development of the campus to better serve students and promote health, and were open to investigating any health related issues of priority for the community including food.

\section{The Pilot Study}

Campus food was an issue first raised during the pilot study. The pilot was designed to test the feasibility of using CB-PAR methods to guide setting based health promotion (WHO, Ottawa Charter, 1986) on a campus. An additional feasibility question was whether student researchers would have the ability to engage the campus community and whether community members would be willing to bring forward their ideas and work together to improve issues rather than looking for others to "fix things". Five students completing health practicum and nutrition courses were keen to investigate campus food. These student researchers, with the 
support of the core research team, were able to engage members of the university community, conduct a small community survey, organize a task group of diverse stakeholders group and create and evaluate several changes to food services. High levels of dissatisfaction with campus food were found in the initial small survey. Observations by the student researchers and assessment by a faculty nutritionist validated the concern. The food task group had representation from students living on and off campus, campus food vendors, senior administration, residence management, student health services, Student Union and health faculty. The student researchers worked diligently to create an atmosphere wherein members would identify their interests, bring forward divergent issues and act to improve campus food. This lively group of campus stakeholders with competing agendas was the precursor of the VOICE Food Action Group.

Several forms of research supported the task group's work: a literature review of best practices in campus food services and characteristics of most highly rated services, campus survey results from the students' research, and vendors' research and results from a national student health assessment. In the pilot work, students and organizational leaders worked in partnership using CB-PAR methods and setting based health promotion strategies to tackle this complex and troubling issue, thus confirming the feasibility of study approach and the value of integrating formal research throughout the process. Further, the process generated enthusiasm and a sense of possibilities. Student researchers wrote letters of support for an external grant proposal and other food task force members offered to participate in future campus food action research. This support was key to obtaining funding.

\section{Food, CB-PAR and Setting Based Health Promotion Strategies}

Throughout the VOICE Study \#1, campus food was a favorite priority issue and focal point of activity, characterized by many successes, challenges and some failures. The VOICE Food Action Group that evolved from the pilot food task group sought to understand more fully the changing campus situation and to take actions to influence changes in people, policy (organizational practices) and the environment. The food related work by the students and organizational leaders included all key elements of CB-PAR with many iterative cycles of community engagement, issues clarification, partnership re-formation, creative planning, critical questioning, small research and evaluation initiatives (requiring data collection and analysis), use of results to guide action including education, and periodic reflection followed by refocusing and renewal. Actions incorporated all five Ottawa Charter setting based health promotion strategies (see Table 1). Some strategies overlapped, such as, the provision of healthy food samples increased participation and education of the community. 
Table 1

\begin{tabular}{|c|c|}
\hline $\begin{array}{l}\text { Setting Based Health Promotion: } \\
5 \text { Areas of Action (Ottawa Charter) }\end{array}$ & Examples of Action Taken on Campus \\
\hline 1) Build Healthy Public Policy: & $\begin{array}{l}\text {-Promote competition in food services } \\
\text {-Support extending meal plans to all vendors } \\
\text { offering healthier options } \\
\text {-Endorse practices to decrease fat, sugar \& } \\
\text { salt in food preparation }\end{array}$ \\
\hline 2) Create Supportive Environments: & $\begin{array}{l}\text {-Position healthy food to be more visible } \\
\text {-Challenge vendors to create some less costly } \\
\text { healthy foods } \\
\text { - Bring local \& organic foods to campus } \\
\text {-Promote vendors' healthier items } \\
\text { - Increase unprocessed food options }\end{array}$ \\
\hline 3) Strengthen Community Action: & $\begin{array}{l}\text {-Increase opportunities for everyone to } \\
\text { participate as stakeholders ("raise voice") } \\
\text {-Create "healthy campus" research visibility } \\
\text {-Sustain Food Action Group } \\
\text {-Support special interest groups (i.e. "real" } \\
\text { food, gardening, allergies) }\end{array}$ \\
\hline 4) Develop Personal Skills: & $\begin{array}{l}\text {-Seminars re: how to shop, cook \& eat healthy } \\
\text { - Health info boards \& print materials } \\
\text {-Conduct taste testing } \\
\text {-Demonstrate label reading, navigating food } \\
\text { outlets \& healthier food at events }\end{array}$ \\
\hline 5) Reorient Health (Related*) Services: & $\begin{array}{l}\text {-Choose a more health conscious snack } \\
\text { vendor with students involved in process } \\
\text {-Integrate VOICE methods into student health } \\
\text { and counselling services }\end{array}$ \\
\hline
\end{tabular}

*The inclusion of health related as well as traditional health services meant that a wider range of campus services were invited to reorient their work toward prevention and health promotion.

\section{Baseline and Follow up: Assessment of Change}

As discussed previously, results from the initial campus wide Photovoice and Community Dialogue survey $(n=1268)$ indicated that campus food was top ranked among issues "most important to improve", first by students and second by faculty and staff. Participant responses to the questions "what is healthy and unhealthy at the university" comments about the importance of food and the predominance of unhealthy food were frequent. For example, "as soon as we get better food, general health of students in residence will improve", "a healthy campus provides healthy food at a reasonable cost", " too much junk food and unhealthy food", "unhealthy food is highly visible, always available and cheaper than healthy food", 
"we need more healthy foods in vending machines" and "healthy foods should be PROMOTED over and above being simply available."

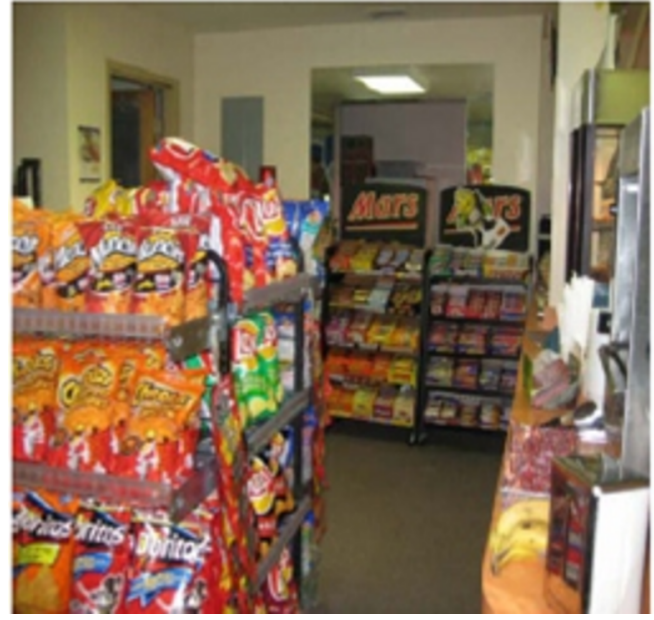

Photovoice Baseline: Healthier Food in back

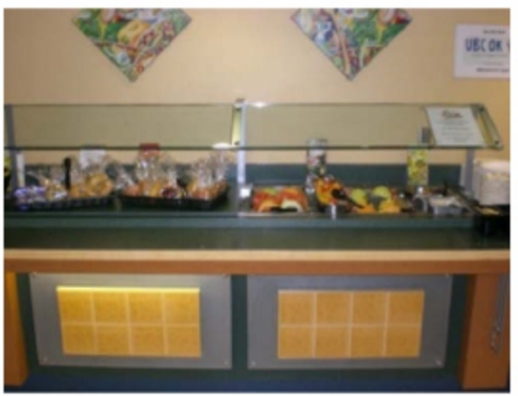

Photovoice Baseline: Mostly Pastries at Breakfast bar

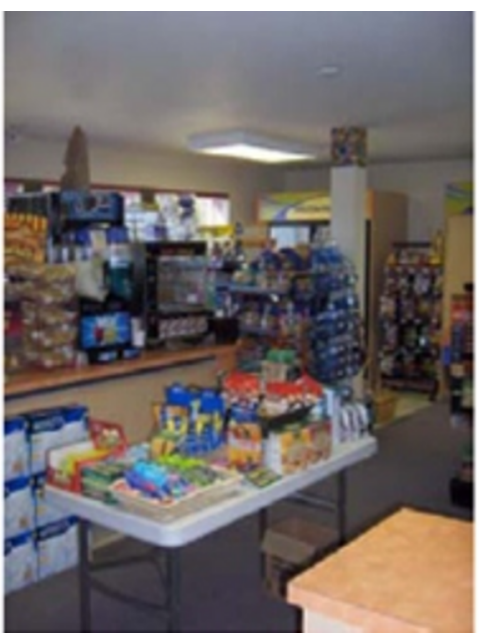

Photovoice Follow-up: Healthier Food in Front

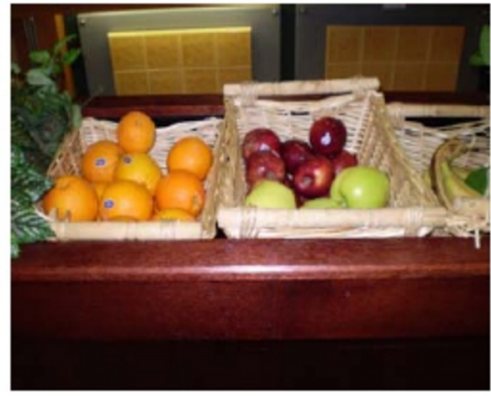

Photovoice Follow-up: Fruit Available at Breakfast Bar

In the mid point community re-assessment, Community Dialogue survey participants ( $n=672$ ) were asked to rank the same 12 issues as identified in the first survey according to changes that had been noticed. Food improvements were top ranked by all participants (students, faculty and staff) and by students living on campus. Students living off campus ranked improvements in drinking water as most noticeable. Comments about food were: "healthy options are more available", "cafeteria and Simi Store (residence store) have been changed for the better: more fruit, vegetables, salads, cereal and organic options" and "Good healthy changes, need more!"

In the third year, the Food Action focus shifted to following through on previous research results and recommendations, reflection, renewal and sustaining healthy change. For example, 
the snack vending machine content had shifted away from the healthy changes made earlier in response to student feedback and new provincial guidelines. Student researchers worked with the vending company to reestablish priority placement of healthier snacks, improve labeling and offer new options. At the end of semester campus wide VOICE forum, the students demonstrated snack food label interpretation and promoted healthier snacks with samples provided by the company. At the same time, fresh fruit and veggies were given out in large numbers to illustrate cost and nutrition (e.g. apple versus bag of baked chips).

Further evidence of campus food changes over time was provided by results from the National College Health Assessment (NCHA). NCHA is a North American standardized higher education survey that is conducted at the study campus every few years so that trends in student health can be assessed. In $2006,53 \%$ of NCHA participants at the study campus were dissatisfied with campus food; in 2009, 44\% were dissatisfied (see Graph 1 for campus). This statistically significant $(\mathrm{p}=.001)$ improvement in student satisfaction was interpreted as another indicator of positive outcomes, partially influenced by VOICE Study actions and partially the result of other factors such as new buildings with food outlets. However, participants also reported that they were eating fewer vegetables in 2009 than $2006(p=.05)$. This finding indicated that food health promotion activities continue to be important to student health and chronic disease prevention.

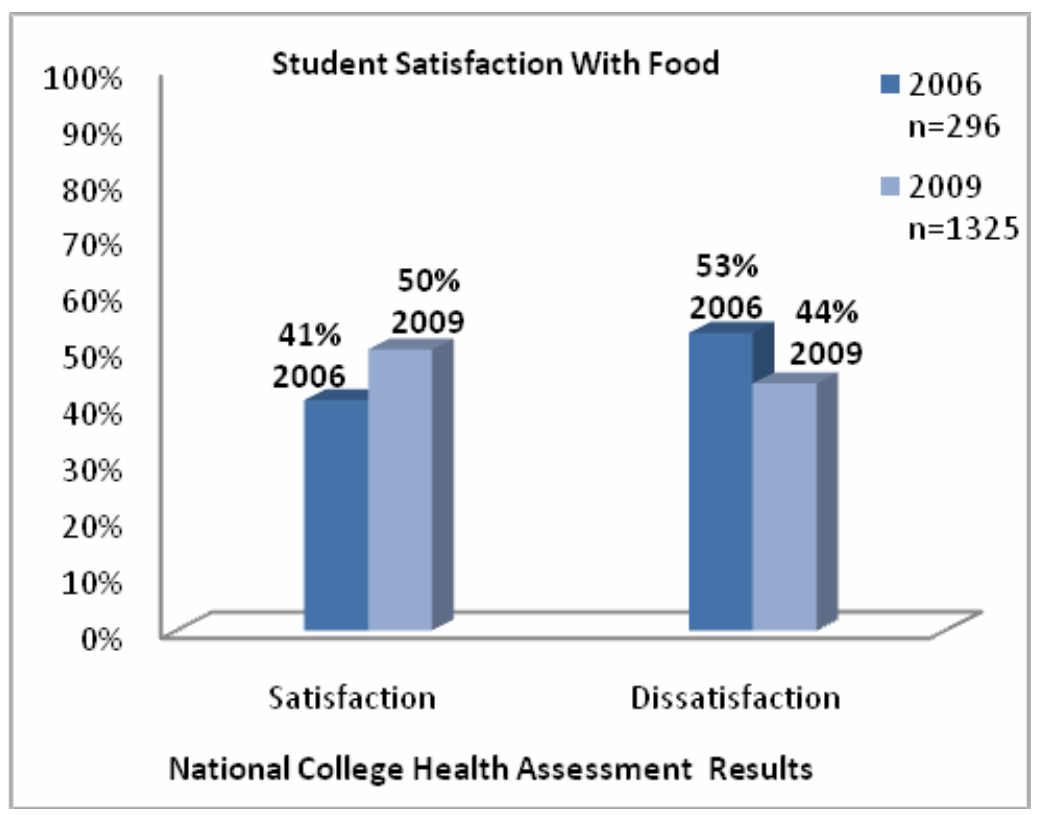

Graph 1

\section{The New Campus Food Context}

By the end of the study, there were many new campus buildings and food outlets. A notable change in policy and practices was allowing the Student Union to become a food vendor 
and to qualify for student meal plan use. The Food Action Group had promoted this strategy because it was used at a Canadian campus known for high student satisfaction with food. The strategy simultaneously supported student economic and health interests, and economic and service interests of external food vendors and the Student Union. At the study campus, access to healthier and less costly food options increased. The Food Action Group changed to accommodate the numerous shifts in the campus context. Emerging student interests in community gardening, allergy issues and vegetarian eating became a focus for increased action.

Sample of Photovoice Results to Illustrate Ottawa Charter Health Promotion Strategies

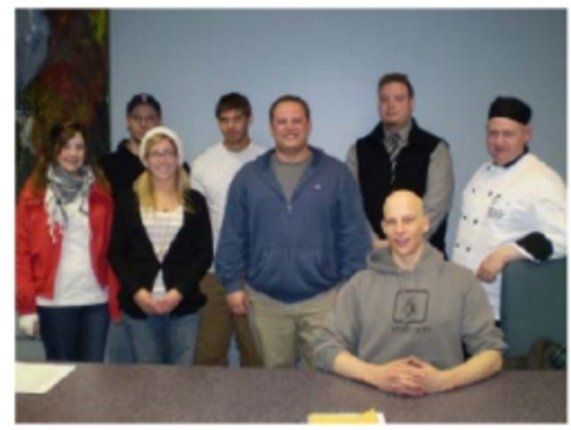

Photovoice: Food Action Group Photovoice:

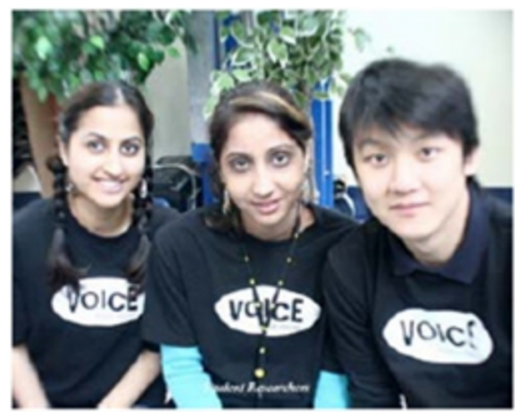

Photovoice: "Healthy Campus" Action Visibility

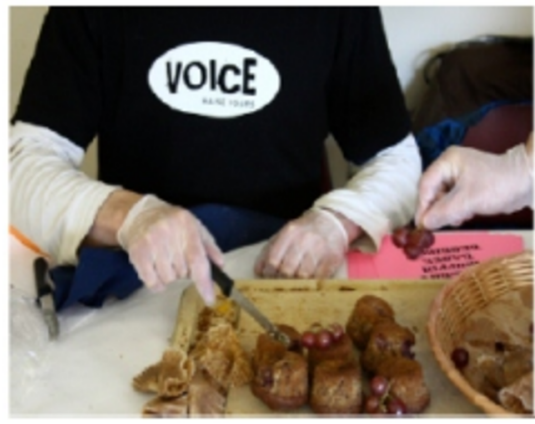

Taste testing healthy food options

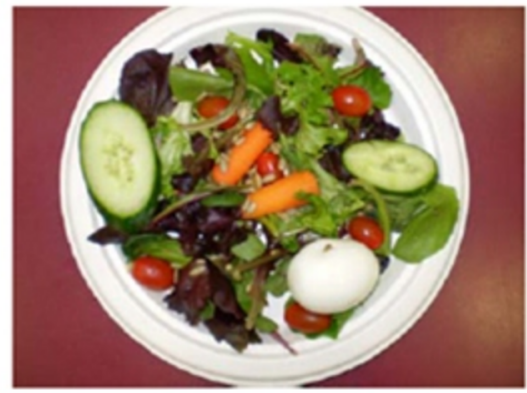

Photovoice: Low Cost Salad from Salad Bar

\section{Collaboration and Mutual Support}

Practical supports were numerous, all Food Action group members and other community participants contributed to the process. A pattern of helping each other developed. For example, faculty helped students to ensure their work was of high quality, students helped food vendors locate and conduct taste tests with new products, students from health, arts, science and management programs received course or volunteer credit depending on their individual arrangements with faculty, the student health and counseling unit provided working and meeting space and group members helped each other stay in touch through in person contact, meetings and electronic communication. The cross section of people involved helped to keep 
information up to date and activities responsive to the rapid campus growth. Small changes sometimes had a large impact. For example, when residence move in and registration line up numbers exceeded expectations, Food Action Group members worked with local farmers to provide fresh fruit to waiting students and their families. The response was so positive that fresh local fruit became a common part of move in weekend and campus events. Several local farmers have become regular suppliers for the campus.

\section{Finding Common Ground}

While the students primarily were focused on the goals of increasing availability of healthier food and less expensive food options, the food vendors' primary goal was "meeting bottom line" interests. The only goal the diverse stakeholders initially could agree upon was to increase student satisfaction with campus food. Not surprisingly, ideas about how to achieve this goal often conflicted. Nevertheless, the students and organizational leaders found ways to establish common ground and work together. Over time, as the VOICE Food Action Group members changed and the campus context shifted dramatically, the common goals gradually evolved to increasing student satisfaction and access to "healthy" food on campus. Both students and organizational leaders became more interested in environmental sustainability and practices that are respectful of both consumer (student) and business interests. Throughout this study, the use of research methods helped neutralize conflicts and decrease sensitivity about the inclusion of participants' own practices and policies in the investigation. Researchers found it helpful to regularly make explicit the value of respect: "we all are doing the best we can given what we know and are trying to accomplish".

\section{Two Steps Forward, One Step Back}

Many positive healthier food changes were made, however, backward motion was common due to several factors. For example, taste testing and introduction of healthy muffins and fresh local fruit were followed by an increase in sales. Although healthy muffins were popular, the logistics of preparation were difficult given limited food preparation facilities thus the muffins were discontinued; fruit was continued. In spite of the partial set back, student comments on surveys indicated that the efforts to improve food were appreciated and in the right direction. In 2008, a national magazine evaluation of Canadian campus food services, evaluated the availability of fruit as an outstanding feature on the study campus (Millar 2009). Fresh local fruit became even more available and highly visible in the food outlets of a new student centre that opened in 2009. Also, healthier muffins reappeared with new managers and chefs, the development of competitive new food outlets and increased capacity for food preparation.

\section{Sustaining the Work}

The student researchers were central to the food actions and passed their work along to other interested students with the support of faculty and the core research team. This "pass the baton" style was used throughout the VOICE Study to promote building upon previous work and to sustain momentum. The student health and counseling unit eventually incorporated 
the VOICE methodological framework into their community programming as a way to sustain prevention work and create change relevant to students.

In summary, changes occurred during the study such as improved access to healthier foods and increased student satisfaction. The use of the VOICE Study methodological framework contributed to the changes, i.e. CB-PAR and setting based health promotion strategies used in combination with student and organizational partnerships. The campus is a microcosm of society and access to healthier and cost-effective food options is an ongoing challenge. Improvements continue to be made, even as, new unhealthy products appear.

\section{Discussion}

The main challenges overall in the study were navigating competing interests; maintaining energetic, egalitarian partnerships; forming new relationships and refocusing activities when "players" and the environment changed; and managing the untidiness of a dynamic research and community development process. The core research team managed the challenges through ongoing mentoring and training of the student researchers and project workers, and support from organizational leaders.

The foundational theories proved useful in keeping study goals in focus and the process on track. Theoretical models were brought forward for review when clarity was needed in discussions. The community ecosystem and healthy community theories provided explanations about why all aspects of the community were of interest and the contributions of everyone were valued. The cyclical process of research, action and education/dissemination created widespread participation and ownership. The use of research methods added credibility and moved the discussion of diverse views into exploratory rather than adversarial space. The extensive participation in the work of improving the campus, stimulated enthusiasm and creativity, and ultimately many practical actions were taken and resources were creatively mobilized.

\section{Future Research}

While positive changes occurred and new insights were generated about the effectiveness of using community-based action research methods in combination with health promotion strategies and student and organizational leader partnerships, sustainability was a concern. The researchers, students and organizational leaders observed that changes could "change" quickly. The concern of course is about negative shifts, for example, when "appealing but unhealthy" new food products came on the market and unhealthy options again dominated vending machines and store shelves. Another concern worthy of investigation is the energy expenditure required to form new partnerships when people change positions, such as, a new organizational leader who is unfamiliar with the benefits of working in partnership with students.

VOICE Study \#2 is underway, as the methodological framework has achieved credibility as a practical way to improve campus issues that are health related. Students and organizational leaders have approached the VOICE team to inquire about working with VOICE and with suggestions about issues to investigate. Our new research question is "How can healthpromoting campus change be sustained given diverse interests?" We are wondering whether a longer experience with CB-PAR, setting based health promotion and student/organizational 
BUDGEN, CALLAGHAN, GAMBLE, WIEBE, REIMER, FEDDERSEN,

DUNN, JOHNSON, MCHUGH, MORRISON, SULLIVAN, CULL,

ABD-EL-AZIZ

leader partnerships, might have the effect of embedding the theoretical concepts and principles further into the practices of the campus community, thereby creating more sustainable change. Also, organizational leaders from other campuses have expressed interest in learning about the applicability of the study results for their environments. The researchers have found that the VOICE methodological framework is transferable when the egalitarian values embedded in the framework are explicit and the community designs the specifics to fit their context. 


\section{References}

Bader, R., Wanono, R., Hamden, S., \& Skinner, H.A. (2007). Global youth voices: Engaging Bedouin youth in health promotion in the Middle East. Canadian Journal of Public Health, JanuaryFebruary, 21-25.

Brydon-Miller, M. (2001). Education, research and action: Theory and methods of participatory action research. In Tolman, D.L and Brydon-Miller, M. (Eds.), From subjects to subjectivities: A handbook of interpretive and participatory methods (pp. 76-89). New York, NY: New York University Press.

Budgen, C., Cameron, G., \& Bartfay, W. (2010). Program planning, implementation, and evaluation. In J. E. Hitchcock, P. E. Schubert, S. A. Thomas, \& W. Bartfay (Eds.), Community Health Nursing: Caring in Action (1st Canadian Ed ) (pp. 284-324). Toronto Ontario: Nelson Education.

Checkoway, B., Allison, T., \& Montoya, C. (2005). Youth participation in public policy at the municipal level. Children and Youth Services Review, 27, 1149-1162.

Denzin, N.K., \& Lincoln, Y.S. (2000). The Handbook of Qualitative Research (2 ${ }^{\text {nd }}$. Ed.) Thousand Oaks, CA: Sage.

Doherty, S., \& Dooris, M. (2006). The healthy settings approach: The growing interest within colleges and universities. Education and Health, 24(3), 42-45.

Dooris M., \& Doherty, S. (2009). National Research and Development Project on Healthy Universities: Final Report. London: Higher Education Academy Health Sciences and Practice Subject Centre.

Dooris, M. (2005). Healthy settings: Challenges to generating evidence of effectiveness. Health Promotion International, 21(1), 55-65.

Freire, P. (1970/1993). Pedagogy of the Oppressed (20 ${ }^{\text {th }}$ Ed). New York: Continuum.

Government of Southern Australia. Children, Youth and Women's Health (2010). Young Adult Health Ages 18-25 Healthy Eating. Retrieved from http://www.cyh.com/HealthTopics/ HealthTopicDetails.aspx?p=240\&id=1998\&np=297

Green, L.W., George, M.A., Daniel, M., Frankish, C.J., Herbert, C.J., Bowie, W.R., \& O’Neil, M. (2003). Appendix C: Guidelines for participatory research in health promotion. In M. Minkler \& N. Wallerstein (Eds.), Community-Based Participatory Research for Health (pp. 419-428). San Francisco: Jossey-Bass.

Hancock, T. (1993a). Health, human development \& the community ecosystem: Three ecological models. Health Promotion International, 8(1) 41-47.

Hancock, T. (1993b). The evolution, impact, and significance of the Healthy Cities/Healthy Communities Movement. Journal of Public Health Policy, 14(1), 5-18.

Larson, R.W., Hansen, D.M., \& Moneta, G. (2006). Differing profiles of developmental experiences across types of organized youth activities. Developmental Psychology, 42(5), 849-863.

Millar, E. (2009, January 26). Campus Chow: University of British Columbia-Okanagan - the cafeteria. Maclean's . Retrieved from http://www.macleans.ca/oncampus

Ministry of Health (1989). Healthy Communities: The Process. Victoria B.C.: Author.

Minkler, M., \& Wallerstein, N. (Eds.) (2003). Community-Based Participatory Research for Health. San Francisco: Jossey-Bass.

Morse, J.M. (1999). Qualitative methods: The state of the art. Qualitative Health Research, 9, 393406.

Reger, B., Williams, K., Kolar, M., Smith, H., \& William Douglas, J. (2002). Implementing universitybased wellness: A participatory planning approach. Health Promotion Practice, 3(4), 507514.

Ridgley, A., Maley, O., \& Skinner, H.A. (2004). Youth voices: Engaging youth in health promotion using media technologies. Canadian Issues, Association for Canadian Studies, Fall, 21-24. 
Satcher, D. (2005). Forward. In B.A. Israel, E. Eng, A.J. Shulz, \& E.A. Parker (Eds.), Methods in Community-Based Participatory Research for Health (pp. xiii-xiv). San Francisco: JosseyBass.

Tsouros, A.G., Dowding, G., Thompson, J., \& Dooris, M. (1998). Health Promoting Universities: Concept, Experience and Framework for Action. WHO Regional Office for Europe, Copenhagen.

U.S. Department of Health and Human Services . Centers for Disease Control and Prevention. (2008). Nutrition and the Health of Young People. Retrieved from http:www.cdc.gov/HealthyYouth/Nutrition

Wallerstein, N., \& Duran, B. (2003). The conceptual, historical, and practice roots of community based participatory research and related participatory traditions. In M. Minkler \& N. Wallerstein (Eds.), Community-Based Participatory Research for Health (pp. 27-52). San Francisco: Jossey-Bass.

Wang, C.C. (2003). Using photovoice as a participatory assessment and issue selection tool: A case study with the homeless in Ann Arbor. In M. Minkler \& N. Wallerstein (Eds.), CommunityBased Participatory Research for Health (pp. 179-196). San Francisco: Jossey-Bass.

Wang, C.C., \& Burris, M. (1997). Photovoice: concept, methodology, and use for participatory needs assessment. Health Education and Behavior, 24, 369-387.

World Health Organization. (1986). Ottawa Charter for Health Promotion. Ottawa, Canada: Canadian Public Health Association.

Xiangyang, T., Lan, Z., Xueping, M., Tao, Z., Yuzhen, S., \& Jagusztyn, M. (2003). Beijing health promoting universities: Practices and evaluation. Health Promotion International, 18 (2), 107-113.

\section{About the Authors}

Dr. Claire Budgen

RN, BSN (University of Washington), MSN (University of California San Francisco), PHD (University of Texas Austin). Dr. Budgen's nursing practice and research interests include: young adult health; healthy community/campus development; mental health; quality of care; innovative health care systems; qualitative and quantitative research methods. Claire currently is working with an inter-professional team at UBC Okanagan to further develop a health promotion and prevention based student health and counselling unit, where acute treatment and rehabilitation are integrated components, and individual students and the campus community are of interest. She is the principal investigator for the VOICE research.

\section{Doris Callaghan}

RN, MSc (Health Promotion University of Manchester); Associate Professor Nursing. Doris' research interests include healthy living and chronic disease prevention in youth. Current research: tobacco policy at university campuses across Canada and action research methods to create healthy communities/campuses. Doris is a Co-principle investigator with VOICE.

\section{Dr. Diane Gamble}

$\mathrm{RN}, \mathrm{PhD}$ (Nursing U of Alberta), Associate Professor Emerita Nursing, Research and Practice Consultant. Dr. Gamble teaches Relational Practice, Political Action and Nurses Influencing 
Change. Her practice background and research interests are community focused health promotion, healthy university/ college development, midwifery, ethical interpersonal/interprofessional relationships and innovative research methods to explore these concepts. Diane is a Co-principle investigator with VOICE.

\section{Robyn Wiebe}

RN, BSN (UBC Okanagan). Robyn is a graduate student at University of Victoria (UVic). Research interests include equity, public health and community-based research. Robyn works with Health \& Wellness on special projects, research and sustainability initiatives. At UVIC, Robyn is a Research Assistant with the School of Nursing. A current research focus is the emerging field of Public Health Systems/Service Research. Robyn was the Project Coordinator for VOICE for 2 years.

\section{Christopher Reimer}

$\mathrm{RN}, \mathrm{BSN}$ (UBC Okanagan). Chris worked as an undergraduate student researcher on VOICE Study \#1. Following graduation, he joined Health and Wellness at UBC Okanagan to work as a Nurse Clinician. Chris is on the research team for VOICE Study \#2, working as a mentor for student researchers and taking the lead on many projects. He also works in Cardiology at the Kelowna General Regional Hospital.

\section{Melissa Feddersen}

RN BSN (UBC Okanagan). Melissa is a project coordinator and Nurse Clinician with Health and Wellness. Her practice background is public health nursing, illness/injury prevention, camp nursing and youth/student health and wellness. She is engaged in tobacco control research, evaluation and program development work, funded by Health Canada. Melissa has played a key project facilitation role with VOICE since its inception.

\section{Shannon Dunn}

BCommerce (Ryerson University Toronto), graduate student MA Interdisciplinary Studies (UBC Okanagan Health/Health Care). Shannon is Director Housing and Conferences at UBC Okanagan and has been the administrative leader in the rapid food and housing service development. Shannon serves on many internal committees, she is Director of the Emergency Operation Centre for the campus; and externally, in her profession, serving as Chair of the Corporate Relations and Exhibits Committee for the Association of College and University Housing Officers International. She is a strong advocate for student participation in campus decision making and program development, and committed to helping students assume responsibility for their health and for promoting the health of others on campus. Shannon has been a key VOICE team member throughout the study.

\section{Rob Johnson}

Bachelor and Masters in Physical Education (UBC), Associate Professor Education, Director of Athletics and Recreation. Rob has been instrumental in the development of health and fitness opportunities for students, inclusive of a wide range physical and social determinants. $\mathrm{He}$ is a strong supporter of research and programming that involves student input and community participation. Rob has been a key team member since the inception of the VOICE research. 
Natalie McHugh

Natalie is the administrative lead for Aramark on campus, the main food vendor. She has taken a lead role in shaping the food services to be more responsive to student interests including, for example, fresh local fruit, and also, in bringing a business perspective to the VOICE Food Action Group discussions about healthy eating. Her family runs a local orchard which has become a respected provider of high quality, reasonable priced fruit for student programs and events.

\section{Heidi Morrison}

RN, BSN (UBC Okanagan) Practice background Public Health, Sexual Health and Maternity. Her work as a Nurse Clinician at Health \& Wellness has included extensive work with VOICE and the Food Action Group. She is especially adept at helping students and organizational leaders work collaboratively and in a forward direction.

\section{Kelli Sullivan}

MA (Family Studies). Kelli's research interests include parent-adolescent relationships, youth health and gender-based analysis. During the VOICES project Kelli was working on her $\mathrm{PhD}$ in Interdisciplinary Health Studies. She currently works with the Faculty of Health and Social Development as a Health Research Facilitator. She was a research associate during the pilot study and continues to contribute to VOICE proposal and project development and dissemination.

\section{Ian Cull}

Honours BA, MA (Clinical Psychology) (Lakehead University), Honours BA (Anthropology/Archaeology ((McMaster University). Ian has been in the position of Associate Vice President, Students, at the Okanagan Campus of the University of British Columbia since its inception in 2005. As a senior executive and senior student affairs officer with a large portfolio of services for students, his contribution of time and support for the VOICE research program has been a key to its ongoing relevance to students and organizational leaders. Ian has contributed a practical and creative approach to people and problems, interest in undergraduate student engagement in research, and time when needed by the team. Ian is a member of Dokis Indian Band in Ontario.

\section{Dr. Alaa Abd-El-Aziz}

BSc, MSc (Ain Shams University Cairo), PhD (University of Saskatchewan), NSERC Postdoctoral Fellowship (University of Toronto. Dr. Abd-El-Aziz is the President and ViceChancellor, University of Prince Edward Island. During the VOICE Study \#1 he was Provost and Associate Vice President Academic and Research at UBC Okanagan Campus. As a senior executive and chemistry professor, Alaa has contributed unique expertise and considerable time to VOICE, demonstrating his commitment to teaching and to involving students and other members of the campus in research. He has willingly worked across disciplines and departments to investigate questions about the campus and solve problems. Alaa is a prolific researcher with numerous grants, publications and presentations to his credit. 